\title{
Effects of Selective Laser Melting Parameters on Relative Density of AlSi10Mg
}

\author{
Aqeel Ahmed ${ }^{1}$, M. S. Wahab ${ }^{1}$, A. A. Raus ${ }^{1}$, K. Kamarudin ${ }^{1}$, \\ Qadir Bakhsh ${ }^{1}$ and Danish Ali ${ }^{1}$ \\ ${ }^{1}$ Faculty of Mechanical and Manufacturing Engineering \\ Universiti Tun Hussein Onn Malaysia, Parit Raja, Batu Pahat, Johor, Malaysia \\ aqeelbhutto03@yahoo.com, saidin@uthm.edu.my; qmh6555@gmail.com; khairu.uthm@gmail.com; \\ qadirquest@gmail.com; danishmemon2013@yahoo.com \\ A.A Raus1, M.S Wahab1, M. Ibrahim1, K. Kamarudin1, Aqeel Ahmed1, S Shamsudin1
}

\begin{abstract}
Selective Laser Melting (SLM) is an advance Additive Manufacturing (AM) technique in which a component is manufacturing in a layer by layer manner by melting the top surface of a powder bed with a high intensity laser according to sliced 3D CAD data. AlSi10Mg alloy is a traditional cast alloy that is often used for die-casting. Because of its good mechanical and other properties, this alloy has been widely used in the automotive industry. In this work, the effects on the relative density is investigated for SLM-produced AISi10Mg parts on one factor at a time (OFAT) basis by keeping constant various parameters such as laser power, scanning speed and hatching distance. It is shown that AlSi10Mg parts produced by SLM having best relative density values are at 350 watt laser power, $1650 \mathrm{~mm} / \mathrm{s} \mathrm{of} \mathrm{scanning}$ speed and hatching distance of $0.13 \mathrm{~mm}$.
\end{abstract}

Keywords-Additive Manufacturing; Selective Laser Melting; Selective Laser MeltingParameters; AlSi10Mg; Relative Density.

\section{INTRODUCTION}

Selective Laser Melting (SLM) is a rapid manufacturing technology to manufacture complex shape and near net-shaped components from computer aided design (CAD) data. The working mechanism of SLM processing can be defined as: Creating the engineering component model from 3D-CAD software and convert it to standard STL format.Slice the STL model into horizontal layers with a certain thickness (usually $20-50 \mu \mathrm{m}$ ) in the computer control center of the SLM facility. Spread a layer of metal powder on the top of the building platform. Melt and fuse the powder by a laser beam, as it traces the geometry of the generated slice. Lower the fused layer and spread a new layer of powder with the recoated. Laser scan the new surface and fuse the metal particles to each other and to the lower layer. Repeat the process until the component is fully fabricated. Finally, remove the part from the machine and sieve back the unsintered powder to the powder dispenser for reuse [1-4].

AlSi10Mg is a typical casting alloy with virtuous casting properties and is typically used for cast parts with thin walls and complex geometry and it provides good strength, hardness and dynamic properties and is therefore also used for parts subject to high loads [5]. Conventionally cast components in this type of aluminum alloy are often heat treated to improve the mechanical properties, for example using the T6 cycle of solution annealing, quenching and age hardening [6]. The laser-sintering process is characterized by extremely rapid melting and re-solidification and produces a metallurgy and corresponding mechanical properties in the as-built condition which is similar to T6 heat-treated cast parts therefore such hardening heat treatments are not recommended for laser-sintered parts, but rather a stress relieving cycle of 2 hours at $300^{\circ} \mathrm{C}\left(572{ }^{\circ} \mathrm{F}\right)$ [7]. Due to the layer wise building method, the parts have a certain anisotropy, which can be reduced or removed by appropriate heat treatment [8].

\section{AISi10Mg ALLOY MOLDS}

AlSi10Mg alloy aluminiummoulds are utilized for high-volume production and are considered as an attractive preference for an increasing number of applications because it can decrease cycle times intensely, speedup the mould manufacturing time, and reduce tooling costs [9]. An effective application utilizing an AlSi10Mg alloy Aluminium Injection Mould will typically operate $20 \%$ to $40 \%$ faster than the same part operating in a steel mould and benefitted into a cost advantage for the moulder and customer [10].

Researches on the AlSi10Mg alloy moulds have shown that the alloy has low interfacial heat resistance (High Conductivity) and will remove heat from the plastic melt even during injecting and not only during the cooling time of the component. It is significant to counter act this fast cooling phenomena of AlSi10Mg alloy mould by using slightly faster the speed of supply material and slightly elevated mold temperatures to counteract surface blemishes caused by quick injection/melt/solidification. However, even with slightly higher 
mold set temperatures (10 - 20 degrees) the plastics solidification will occur more quickly than with steel molds, therefore result is faster melt solidification and shorter cooling/ cycle times [11 and 12].

There are many factors that affect the relative density of the SLM fabricated samples such as: the raw material characteristics (powder size, morphology and size distribution), the laser heat input, laser power, scanning speed and hatching distance. Some studies [13] used the energy density concept to compare the porosity development with the heat input, but the trend was generally unpredictable, although it recognized as an optimal energy density level where the build density can be maximum. Alternatively, the use of design of experiments (DOE) methods such as the Response Surface Method, statistical analysis using the analysis of variance (ANOVA), one factor at a time (OFAT) method and many more have been shown to be useful approaches to study the effect of parameters in SLM material processing applications [14]. This paper focuses on the effect of SLM parameters such laser power, scanning speed and hatching distance for fabricating $\mathrm{AlSi} 10 \mathrm{Mg}$ to find relative density of the samples.

\section{A. Material}

\section{MATERIAL AND EXPERIMENTS}

Besides the effect of processing parameters, the size, shape, particles distribution and chemical composition of the powder have a significant influence in the melting and fusing activity. The chemical composition of the AlSi10Mg powder having sieving powder of 63 micron, loose density of $7.68 \mathrm{~g} / \mathrm{cm}^{3}$ and was supplied by LPW Technology Ltd is shown in Table I. In this research work, the powder was sowed on a double-sided carbon tape and softly shaken to assure a thin layer of powder being left on the sample block.

TABLE I. Chemical composition of the investigated AISi10Mg alloy (Wt. \%)

\begin{tabular}{lllllllllllll}
\hline $\mathrm{Cu}$ & $\mathrm{Fe}$ & $\mathrm{Mg}$ & $\mathrm{Mn}$ & $\mathrm{N}$ & $\mathrm{Ni}$ & $\mathrm{Pb}$ & $\mathrm{O}$ & $\mathrm{Si}$ & $\mathrm{Sn}$ & $\mathrm{Ti}$ & $\mathrm{Zn}$ & $\mathrm{Al}$ \\
\hline 0.05 & 0.10 & 0.39 & 0.01 & 0.20 & 0.01 & 0.01 & 0.11 & 10.00 & 0.01 & 0.15 & 0.1 & $\mathrm{Bal}$ \\
\hline
\end{tabular}

\section{B. Experimental works}

Using the Selective Laser Melting (SLM) System SLM 125HL 20121213-EN shown in Figure 1 (a) with technical specification mentioned in Table 1, spatial structures can be created layer by layer from a powder-forming metal source material. In the process, the energy of a laser beam is absorbed by the metal powder, resulting in the locally-limited melting of particles. Nearly any three-dimensional form can be construction direction from 3-D construction data in this manner. The SLM process is a cyclical process which consists of three steps which repeat until the end of the construction process. First a recoater (point 2 in figure 1 (b)) applies an even coating of metal powder (point 10 in figure 1 (b)) in layer thicknesses of 20 to $100 \mu \mathrm{m}$. The next step, the exposure, consists of locally solidifying the powder with a laser beam (point 4 in figure 1 (b)). The absorption of the laser radiation causes the metal powder to heat up above the melting temperature of the metal. This causes the blending of the exposed areas of the current layer and the already solidified areas of the layer beneath it through metallurgic melting.

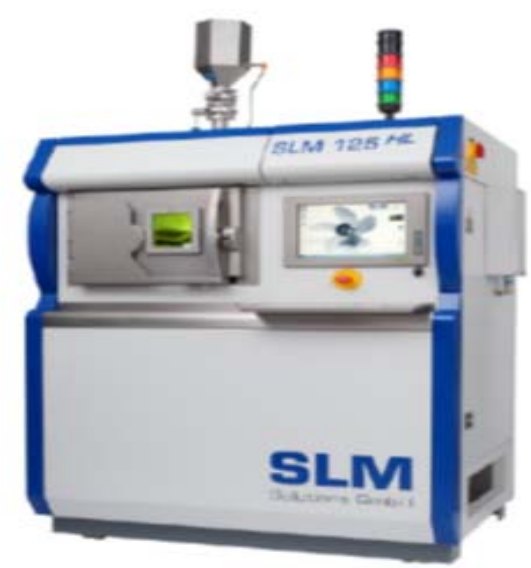

(a)

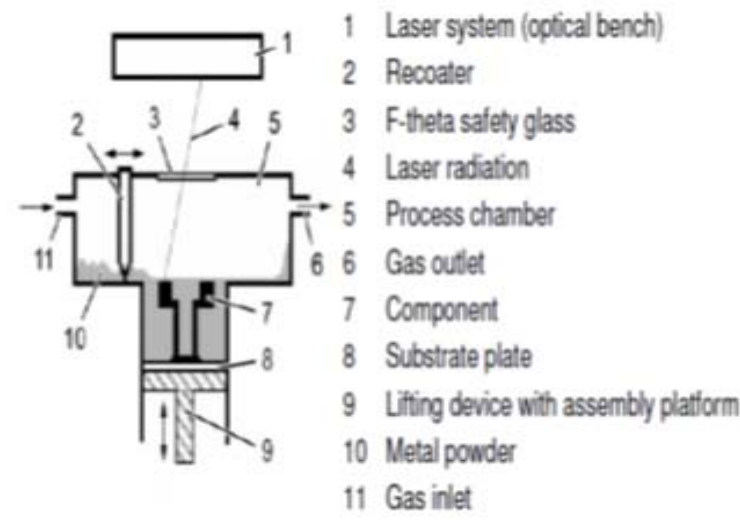

(b)

Fig. 1: Schematic overview of a SLM Machine 
TABLE II. Technical Specification of the SLM System SLM 125HL 20121213-EN

\begin{tabular}{c|l|l} 
S. No: & \multicolumn{1}{|c|}{ Technical Parameters } & \multicolumn{1}{c}{ Values } \\
\hline 1 & Build Envelope $(\mathrm{L}$ x W x H) & $125 \times 125 \times 125 \mathrm{~mm}^{3}$ reduced by substrate plate thickness \\
\hline 2 & 3D Optics Configuration & Single $(1 \times 400 \mathrm{~W})$ IPG fiber laser \\
\hline 3 & Build Rate & up to $25 \mathrm{~cm}^{3} / \mathrm{h}$ \\
\hline 4 & Variable Layer Thickness & $20 \mu \mathrm{m}-75 \mu \mathrm{m}, 1 \mu \mathrm{m}$ increments \\
\hline 5 & Min. Feature Size & $140 \mu \mathrm{m}$ \\
\hline 6 & Beam Focus Diameter & $70 \mu \mathrm{m}-100 \mu \mathrm{m}$ \\
\hline 7 & Max. Scan Speed & $10 \mathrm{~m} / \mathrm{s}$ \\
\hline 8 & Average Inert Gas Consumption in Process & $21 / \mathrm{min}(\operatorname{argon})$ \\
\hline 9 & Average Inert Gas Consumption Purging & $701 / \mathrm{min}(\operatorname{argon})$ \\
\hline 10 & E-Connection / Power Input & 400 Volt $3 \mathrm{NPE}, 32 \mathrm{~A}, 50 / 60 \mathrm{~Hz}, 3 \mathrm{~kW}$ \\
\hline 11 & Dimensions (L x W x H) & $1400 \mathrm{~mm}$ x $900 \mathrm{~mm}$ x $2460 \mathrm{~mm}$ \\
\hline 12 & Weight (incl. / without powder) & approx. $750 \mathrm{~kg} / \mathrm{ca} .700 \mathrm{~kg}$
\end{tabular}

According to the Archimedes method the densities of the substances can be measured by comparing the weight in ethanol, distilled water and air, and expressed in \% relatively to the materials.

$$
\rho_{s}=\frac{m_{s}}{V_{s}} \quad \text { Eq. } 1
$$

Where:

$$
V_{S}=V-V_{H 2 O}^{\prime}=\frac{m_{H 2 O}-m_{H 2 O}^{\prime}}{\rho_{H 2 O}} \quad \text { Eq. } 2
$$

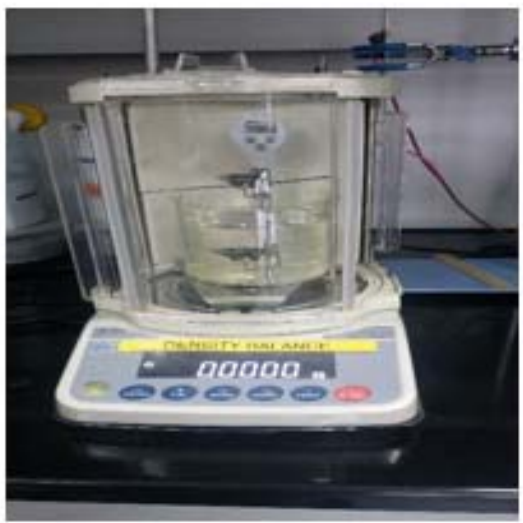

(a)

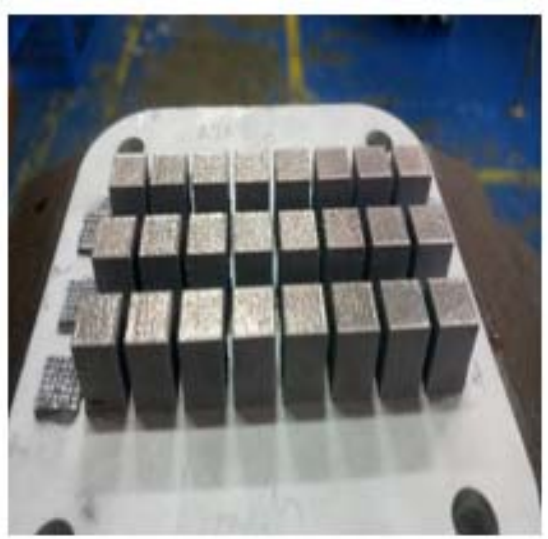

(b)

Fig. 2: Pycnometer and SLM AlSi10Mg Specimen

\section{RESULTS AND DISCUSSION}

\section{Relative Density with Laser Power}

In this study the Archimedes standard method was used to find the density of the SLM processed AlSi10Mg samples and compared with the distilled water in the pycnometer shown in Figure 2 (a) by using equation 1, in the first the laser power in the SLM were ranged from 320 watt to 380 watt and varied with the interval of 6 watt with keeping scanning speed and hatching distance constant at $1650 \mathrm{~mm} / \mathrm{s}$ and $0.13 \mathrm{~mm}$ respectively to find the relative density of the AlSi10Mg powder samples shown in Figure 2 (b), The obtained results are shown in Figure 3. 


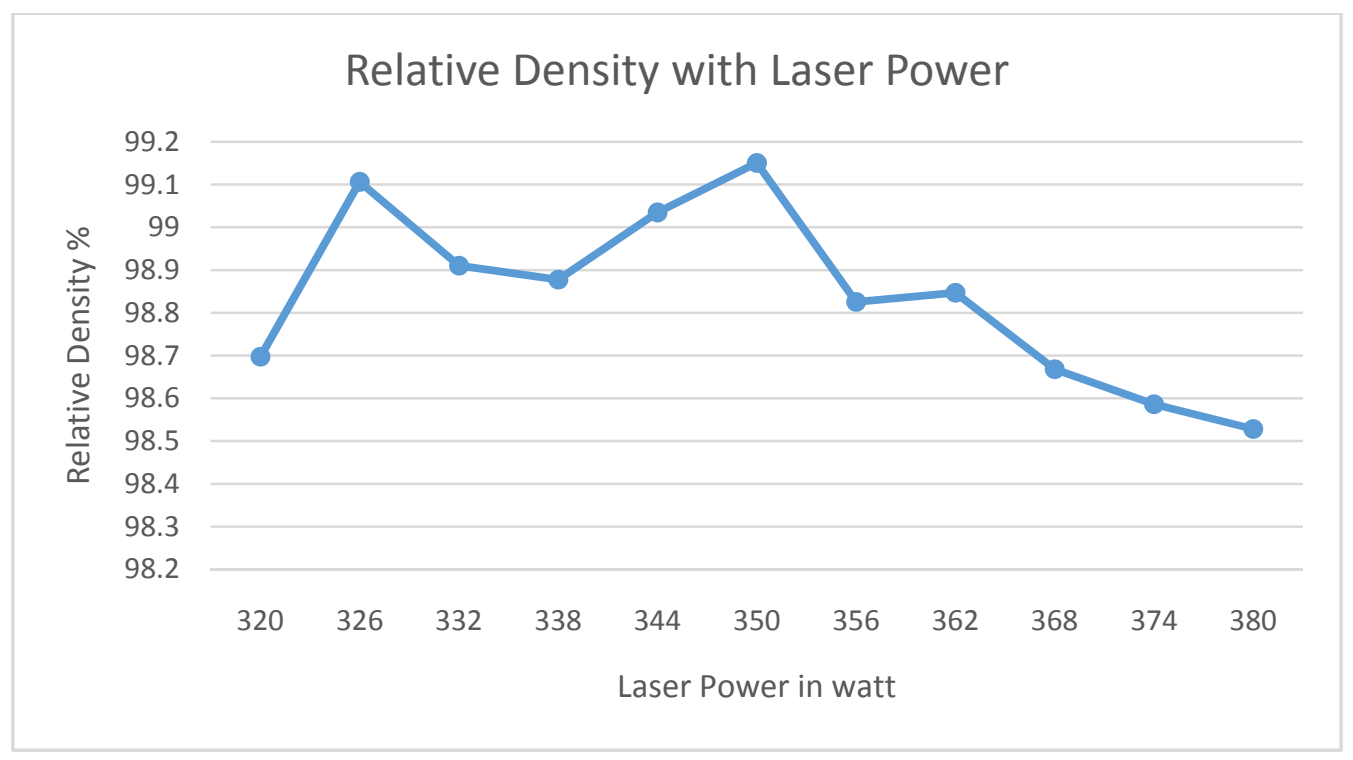

Fig. 3: Relative Density with Laser Power

It is physically difficult to increase the relative density of a specimen without stimulating grain growth of the particles, which results it impossible to isolate and analyse individually. Higher sintering temperature also cause to increase the density of the specimen which expedites the movement of the spins as the number of pores. Thus, a densely sintered microstructure is important for high permeability, as it is important for the imaginary permeability-sintered relative density requirement [16]. Aluminium alloys powders are fundamentally light with poor flow ability and high reflectivity along with high thermal conductivity when compared to other SLM candidate materials; this means that a high laser power is required for melting and to overcome the rapid heat dissipation. Rapid heat dissipation is more important for the solid Al substrate and less common for the $\mathrm{Al}$ powder. Moreover, $\mathrm{Al}$ alloys are highly susceptible to oxidation, which promotes porosity [15 and 17]. One of the major challenges in producing Al alloys parts using SLM is minimizing porosity which directly affects the relative density. Several studies have investigated the effect of processing parameters on relative density [17, 18]. After laser power 350 watt, it cause the reductions in the density results of the material.

D. Relative Density with scanning speed.

The average relative density values for AlSi10Mg samples fabricated through SLM with scanning speed ranging from $1550 \mathrm{~mm} / \mathrm{s}$ to $1750 \mathrm{~mm} / \mathrm{s}$ along with varying at intervals of $20 \mathrm{~mm} / \mathrm{s}$ and keeping constant other two parameters: laser power and hatching distance constant at 350 watt and $0.13 \mathrm{~mm}$ respectively, the obtained result is shown in Figure 4 and the preeminent value of relative density is $99.108 \%$ found at $1650 \mathrm{~mm} / \mathrm{s}$ of scanning speed.

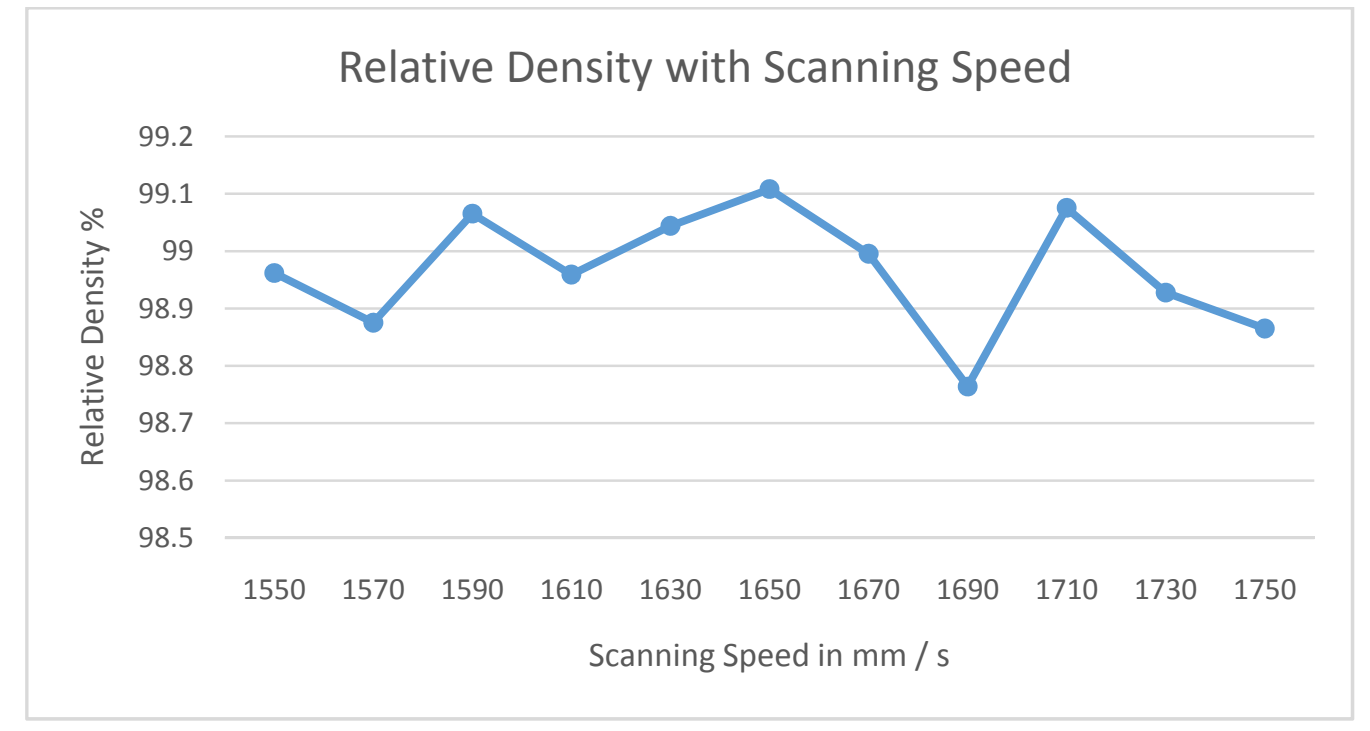

Fig. 4: Relative Density with scanning speed 
However, relative density by itself does not express the whole story, it could be characterized as metallurgical pores and keyhole pores. Metallurgical pores, also recognized as hydrogen porosity and are spherically shaped and small in size (less than $100 \mu \mathrm{m}$ ), whereas keyhole pores are irregularly shaped and large in size (above $100 \mu \mathrm{m}$ ) [19-21]. Metallurgical pores are created at slow scanning speeds from gases trapped within the melt pool or evolved from the powder during consolidation. Keyhole pores arise from keyhole instability, which can be attributed to rapid solidification of the metal without complete filling of gaps with molten metal $[19,20]$.

In most cases, the density of a collection of grains increases as material flows into voids, causing a reduction in overall volume. Mass movements that follow during sintering consist of the decrement of total porosity by repacking, followed by material transport due to evaporation and condensation from diffusion. In the final stages, metal atoms transport along crystal boundaries to the walls of internal pores, redistributing mass from the internal bulk of the object and smoothing pore walls and the surface tension is the driving force for this movement.

\section{E. Relative Density with hatching distance}

The values of relative density data with hatching distance ranging from $0.1 \mathrm{~mm}$ to of $0.15 \mathrm{~mm}$ with intervals of $0.05 \mathrm{~mm}$ with laser power and scanning speed at 350 watt and $1650 \mathrm{~mm} / \mathrm{s}$ constant respectively are shown in Figure 5, the preeminent result for the relative density was $99.34 \%$ at hatching distance of $0.13 \mathrm{~mm}$. Although manufacturing the parts with large hatch spacing is a means for quicker fabrication, it should be noted that larger hatch spacing will require smaller layer thicknesses to confirm both inter-layer and intra-layer overlap resulting the cylindrical or segmental shape of the individual melt pools, i.e. the parts will be sliced into extra number of layers, and hence further time is added [22]. A compromise between the energy density and the speed of fabrication should be considered and concluded that the best overlap was achieved when using hatch spacing values of 0.05 and $0.1 \mathrm{~mm}$. After hatch distance of $0.13 \mathrm{~mm}$, the results showed inverse trends and it is because by increasing further it cause the reductions in the density of the material.

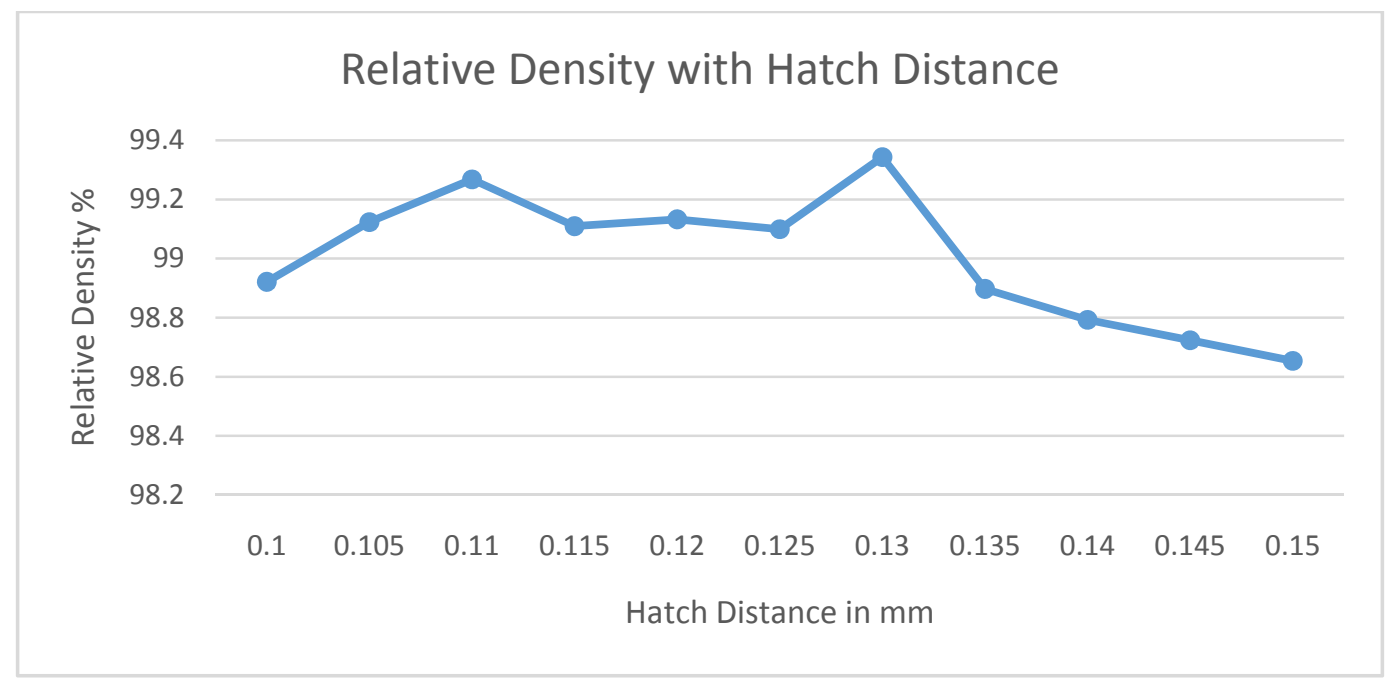

Fig. 5: Relative Density with hatching distance.

\section{CONCLUSION}

After characterization and analysis of the powders' size, morphology and chemical composition through to the assessment of mechanical properties of AlSi10Mg SLM as-fabricated samples, it can be determined that:

1. The OFAT method has been used to evaluate the influence of process parameters on the porosity of SLM processed AlSi10Mg, which shows the trends of porosity in the SLM fabricated samples.

2. The SLM process is controlled by the set of parameters involved in the process of selective laser melting such as scanning speed, hatch spacing, laser power and layer thickness.

3. At constant of scanning speed and hatch distance at $1650 \mathrm{~mm} / \mathrm{s}$ and $0.13 \mathrm{~mm}$ respectively with the variation of laser power from 320 watt to 380 watt having an interval of 6 watt, the preeminent value of relative density is $99.11 \%$ and occurred at laser power of $350 \mathrm{watt}$.

4. At constant laser power and hatch distance at 350 watt and $0.13 \mathrm{~mm}$ along with variation of scan speed from $1550 \mathrm{~mm} / \mathrm{s}$ to $1750 \mathrm{~mm} / \mathrm{s}$ with equal intervals of $20 \mathrm{~mm} / \mathrm{s}$, the good result of relative density is $99.11 \%$ and occurred at $1650 \mathrm{~mm} / \mathrm{s}$.

5. While at constant laser power and scanning speed at350 watt and $1650 \mathrm{~mm} / \mathrm{s}$ and varying the hatch distance from $0.1 \mathrm{~mm}$ to $0.15 \mathrm{~mm}$ with equal intervals of $0.05 \mathrm{~mm}$, the best value of relative density is $99.26 \%$ and occurred at $0.13 \mathrm{~mm}$. 


\section{ACKNOWLEDGEMENT}

This research work is financially supported by Research Innovation Commercialization and Consultancy Management (ORICC) under Grant No. U087, University Tun Hussein Onn Malaysia (UTHM).

\section{REFERENCE}

[1] J. Hanninen, Direct metal laser sintering, Adv. Mater. Process. 160 (2002) 33-36.

[2] EOS takes fine approach to laser sintering, Met. Powder Rep. 56 (2001) 18.

[3] D.T. Pham, S.S. Dimov, Rapid Manufacturing: The Technologies and Applications of Rapid Prototyping and Rapid Tooling, SpringerVerlag, London, UK, 2001.

[4] F. Abe, K. Osakada, M. Shiomi, K. Uematsu, M. Matsumoto, The manufacturing of hard tools from metallic powders by selective laser melting, J. Mater. Process. Technol. 111 (2001) 210-213.

[5] Louvis E, Fox P, Sutcliff CJ. Selective laser melting of aluminum components. J Mater Process Technol 2011; 211:275-84

[6] Kaufman JG. In: Kaufman JG, editor. Properties of aluminum alloys tensile creep and fatigue data at high and low temperatures. Materials Park (Ohio); ASM International (Washington (D.C)); 1999. p. 264.

[7] Olakanmi EO. Selective laser sintering/melting (SLS/SLM) of pure Al, Al-Mg, and Al-Si powders: Effect of processing conditions and powder properties. J Mater Process Technology 2013; 213:1387-405.

[8] Brandl E, Heckenberger U, Holzinger V, Buchbinder D. Additive manufactured AlSi10Mg samples using Selective Laser Melting (SLM): microstructure, high cycle fatigue, and fracture behavior. Mater Des 2012; 34:159-69.

[9] ASM Handbook, Volume 2 Properties and Selection: nonferrous alloys and special-purpose materials, 1990, ASM International The Materials Information Company, United States of America, ISBN 0-87170-379-3, pp.3-14.

[10] Louvis, E., Fox, P. and Sutcliffe,J. Selective laser melting of aluminium components, Journal of Materials Processing Technology 211 (2011), pp. 275-284.

[11] Voncina, M., Mrvar, P. and Medved,J. Thermodynamic analysis of AlSi10Mg alloy. RMZ Materials and Geoenvironment, 52 (3) (2006), pp. 621-633.

[12] Buchbinder, D., Schleifenbaum, H., Heidrich, S., Meiners, W. and Bültmann,J. High power selective laser melting (HP SLM) of Aluminium parts. Physics Procedia 12 (1) (2011), pp. 271- 278.

[13] Olakanmi EO, Cochrane RF, Dalgarno KW. Densification mechanism and microstructural evolution in selective laser sintering of Al12Si powders. J Mater Process Technol 2011; 211:113-21.

[14] Y. Wang, J. Bergstr"om, C. Burman. Characterization of an iron-based laser sintered material. Journal of Materials Processing Technology 172 (2006) 77-87.

[15] K. Kempena, L.Thijs, J. Van Humbeeck and J.P. Kruth. Mechanical properties of AlSi10Mg produced by Selective Laser Melting. Physics Procedia 39 (2012) 439 - 446.

[16] Zhang B, Liao H, Coddet C. Effects of processing parameters on proper-ties of selective laser melting Mg-9\% Al powder mixture. Mater Design2012; 34:753-8.

[17] Louvis E, Fox P, Sutcliffe CJ. Selective laser melting of aluminum components. J Mater Process Technol 2011; 211:275-84.

[18] Kempen K, Thijs L, Yasa E, Badrossamay M, Verheecke W, Kruth J-P.Process optimization and microstructural analysis for selective laser melt-ing of AlSi10Mg; 2011. Available at: http:// utwired. Engr. utexas. edu/ lff/ symposium/ proceedings Archive /pubs / Manuscripts/ 2011/2011-37-Kempen.pdf [accessed May 2014].

[19] Dahotre NB, Harimkar S. Laser fabrication and machining of materials. New York, USA: Springer; 2008.

[20] Xiao R, Zhang X. Problems and issues in laser beam welding of aluminum-lithium alloys. J Manuf Process 2014; 16:166-75.

[21] Haboudou A, Peyre P, Vannes AB, Peix G. Reduction of porosity content generated during Nd:YAG laser welding of A356 and AA5083 aluminum alloys. Mater Sci Eng A 2003;363:40-52.

[22] ASM Handbook, Volume 2 Properties and Selection: nonferrous alloys and special-purpose materials, 1990, ASM International The Materials Information Company, United States of America, ISBN 0-87170-379-3, pp.3-14.

\section{AUTHOR PROFILE}

Aqeel Ahmed Bhutto: PhD Scholar (studying)-Mechanical Engineering, FKMP, UTHM

Prof. Madya Dr. Mohd Saidin Bin Wahab: AMMC, FKMP, UTHM

Azli Amin Bin Ahmad Raus: PhD Scholar (studying)-Mechanical Engineering, FKMP, UTHM.

Khairu Bin Kamarudin: PhD Scholar (studying)-Mechanical Engineering, FKMP, UTHM.

Qadir Bux Jamali: PhD Scholar (studying)-Mechanical Engineering, FKMP, UTHM

Danish Ali Memon: PhD Scholar (studying)-Mechanical Engineering, FKMP, UTHM 